\title{
In Memoriam Alexandre Correia
}

Michel Schooyans

Le Professeur Alexandre Correia s'est éteint à São Paulo le 14 août 1984. Né en 1890 à Porto (Portugal), de parents brésiliens, Alexandre Correia mena de front, à São Paulo, des études de droit et de philosophie. In termina les premières en 1912, se spécialisa en droit romain et devint catedrático de cette discipline à la prestigieuse Faculté de Droit de l'Université de São Paulo. Il occupa cette chaire avec éclat jusqu'à son éméritat. Plusieurs publications spécialisées, fruit de patientes recherches, ponctuérent la carrière du romaniste. Bornonsnous à signaler ici son étude sur $\mathbf{O}$ conceito de ius naturale, gentium, et civile no Direito Romano (1934); et son Manual do Direito Romano, qui connut de nombreuses éditions et fait toujours autorité.

Parallèlement à cette activité de romaniste, le Dr. Correia mena une importante carrière philosophique, qui nous concerne tout particulièrement. Alexandre Correia était sans doute de doyen des docteurs de l'Institut Supérieur de Philosophie. A São Paulo, il avait été l'élève de Mgr Sentroul, qui avait défendu à Louvain une brillante thèse de maîtrise consacrée à Kant et Aristote. Sentroul fut, avec Dom Miguel Kruse, O.S.B., l'un des fondateurs de la Faculté São Bento, et c'est là que Correia fut initié à la philosophie. C'est Sentroul qui envoya son jeune étudiant à l'Institut fondé par Mercier pour y compléter et terminer ses études de philosophie. Correia fut chez nous un des témoins privilégiés de la vie universitaire louvaniste, et il aimait raconter les chahuts, guindailles et autres bagarres linguistiques qui, déjà à l'époque, égayient les brumes du plat pays. Alexandre Correia présenta une thèse de doctorat consacrée à La politique de Joseph de Maistre et la défendit en 1914, juste avant la déclaration de guerre. Rentré aussitôt au Brésil, Correia enseigna le droit et la philosophie. Il publia plu sieurs études sur des thèmes-frontières, en particulier sur le droit naturel.

La carrière philosophique d'Alexandre Correia fut avant toul consacrée à l'enseignament de l'histoire de la philosophie. Selon l'usage de l'époque, il devait couvrir toute l'histoire de la philosophie. Il le fit avec une compétence exemplaire. Sa connaissance approfondie du grec avait fait de lui un familier des présocratiques, de Platon, d'Aristote. Il laisse d'ailleurs dans ce domaine une importante histoire, inédite, de la philosophie grecque. C'est un travail de première main, dont le Maitre n'a pu voir la publication, mais qu'il faudra tôt ou tard mettre à la disposition des spécialistes. Correia excellait également dans l'ex- 
posé de la philosophie moderne. II discutait avec Descartes, conversait avec Malebranche, argumentait avec Leibniz, polémiquait avec Spinoza. Marqué par l'École de Louvain, façon du début du siècle. Correia était un familier de Kant, et nous nous souvenons avec émotion de tel exposé étincelant qu'il fit sur périlleux problème du schématisme

Mais Alexandre Correia était surtout un thomiste convaincu, et certainement un des meilleurs connaisseurs du Docter Angélique que sa génération ait connus. Cet intérêt apparaissait dans son enseignement, ses conférences, ses nombreuses publications. Mais il éclate dans cette oeuvre monumentale qu'est la traduction intégrale, en portugais, de la Somme Théologique de l'Aquinate. Pour mener cette tâche à bien, Correia s'est imposé une discipline de fer : il traduisait un article par jour ; la traduction, précise, est le fruit de plus de 10 ans de labeur. La Somme est rendue dans une langue portugaise d'une rare et pure beauté classique. La première édition fut publiée par la Faculté Sedes Sapientiae, fondée, avec la collaboration éclairée d'Alexandre Correia, par les Chanoinesses de Saint-Augustin à São Paulo. En son extrême vieillesse, Alexandre Correia eut la joie de voir la seconde édition de ce qu'il considérait à juste titre comme l'œuvre de sa vie. Cette édition, magnifiquement présentée, a été procurée conjointement par l'Escola Superior de Teologia de São Lourenço de Brindes, Universidade Caxias do Sul, Livraria Sulina Editora, en collaboration avec l'Universidade Federal do Rio Grande do Sul.

Par son immense érudition, A. Correia était une sorte d'sumaniste de la Renaissance. Il avait tout lu et tout retenu. Sa curiosité intellectuelle était sans limite. Il dominait à la perfection les grandes langues de la culture occidentale. Philosophe et juriste, il ètait aussi familier des grands classiques de la littérature, qu'il lisait toujours dans leur langue originale et dans les meilleures éditions. Il avait aussi exploré les trésors de la littérature portugaise, si injustement méconnue. Sa bibliothèque, riche de quelque trente mille volumes, est, à elle seule, un monument de culture. Correia n'en était pas moins attentif aux problèmes du Brésil de son temps. Polémiste redoutable, il s'est engagé, avec discernement et courage, dans tous les débats de fond qui ont agité l'«intelligentzia» brésilienne au cours des soixante dernières années. Lui qui eût pu faire, comme certains de ses pairs, une brillante carrière d'avocat ou d'homme politique, a cependant toujours refusé de se laisser fasciner par la richesse ou griser par le succès.

Il a opté délibérément, et dès le principe, pour le service intellectuel de ses compatriotes, et ne s'est pas départi un seul instant du dessein qu'il s'était assigné. Epoux attentionné, père de famille à la fois exigeant et libéral, Alexandre Correia suivait de près les débats théologiques de son temps, et il a souffert de quelques excès post-con ciliaires. Cela n'a jamais suffi à entamer sa foi, qu'il avait bâtie sur le roc, et qu'à l'instar de Frère Thomas il alimentait quotidiennement au sacrum convivium. Avec lui, le monde universitaire a perdu un grand seigneur de l'esprit.

Michel Schooyans.

Um mestre, amigo do Dr. Alexandre Correia. 